\title{
A HUMAN ENVIRONMENTALIST APPROACH TO DIFFUSION IN ICT POLICIES
}

\author{
Elaine Byrne \\ University of Pretoria, South Africa \\ Royal College of Surgeons, Ireland \\ Lizette Weilbach \\ University of Pretoria, South Africa
}

\begin{abstract}
This chapter addresses the question: Can a holistic model of ICT adoption and diffusion improve ICT policy formulation? This question is answered by illustrating that in a globalised economy the existing models of ICT adoption are inadequate in explaining the process of adoption and diffusion, and that a human-environmental model can address this gap by explaining the duality of this process. The example of the South African draft White Paper on e-education is used to support this claim.
\end{abstract}

Keywords: ICT Policy; ICT for socio-economic development; ICT adoption and diffusion; ICT implementation context; human environmental model

\section{Introduction}

Developing countries are well aware of the potential benefits of Information and Communication Technology for development: "There was at one time some debate as to whether information and communication technologies (ICTs) were relevant to developing countries, but this debate has been resolved with a clear yes answer. The question has become not whether, but how ICTs can be beneficial" [15]. Many policies promoting the use of ICT have resulted in large investments in ICT infrastructure and launching of e-governance initiatives. Many purport to support both economic and social development. However, when these policies are examined more closely the question of adoption and diffusion is often not, or at best simplistically, addressed. A rather linear trajectory from installation and training to adoption and diffusion is implicit. The basis for these assumptions regarding adoption is related to the rather flat view of the globalised world and resultant linear diffusion models that support this view.

This chapter explores the existing linear and universalistic models of ICT adoption and diffusion which are based on an underlying assumption of a globalised "flat" world (a term popularised by Friedman [6]). This simplistic view

Please use the following format when citing this chapter:

Byrne, E. and Weilbach, L., 2008, in IFIP International Federation for Information Processing, Volume 282; Social Dimensions of Information and Communication Technology Policy; Chrisanthi Avgerou, Matthew L. Smith, Peter van den Besselaar; (Boston: Springer), pp. 209-222. 
of globalisation ignores the structural process of diffusion and adoption. In Section 2 of this chapter we discuss the classical diffusion theories and suggest an alternative model which addresses their shortcomings. The example of the South African ICT education policy [4] is used to illustrate that a more holistic multidimensional model of adoption of ICT - the human environmental model - needs to explore not just the various dimensions of the socio-economic context, but also the process by which these dimensions interact. Greater awareness of all dimensions of the context in which ICTs are proposed to be implemented are acknowledged in the policy, but the process of adoption and diffusion is largely ignored.

Thus, this chapter addresses the question: Can a holistic model to ICT adoption and diffusion improve ICT policy formulation? This question is answered by illustrating that in a globalised economy the existing models of ICT adoption are inadequate in explaining the process of adoption and diffusion, and that a humanenvironmental model can address this gap by explaining the duality of this process.

\section{Diffusion and innovation models}

A one-dimensional view of ICT, inherent assumptions of the "goodness" of ICT, and an assumed linear trajectory from installation and training to adoption and diffusion, is apparent in many ICT policies. However, this assumes a "flat" world and ignores the structural conditions of diffusion and adoption. To take the latter into account implies having more holistic ICT policies based on contextual and socio-economic models of innovation diffusion. General trends, such as total quality management, business process reengineering, and the discourse on globalisation, support the rationale that there are standard ways in which ICTs should be used, and there are specific organisational features which ICTs should aim at supporting [1]. Avgerou [1] calls this approach to the exploitation of ICTs "a-contextual" and warns that it involves high risks of misleading and frustrating local efforts to make sense of and appropriate new technologies. Latter in this section we illustrate a model of ICT adoption and diffusion which can be used instead of these a-contextual models and assist in providing the context needed for a more human-environmental approach to ICT. However, before this discussion we describe some of the a-contextual and contemporary diffusion and adoption models.

In the late 1980's and early 1990's a lot of research in the field of information systems (IS) was done on IS implementation problems [9]. IS implementation research was mainly based on the theories of innovation diffusion, focusing on how the perceptions of the potential users of the information technology (IT) innovation influenced the adoption thereof. One of the most cited innovationdiffusion theories is that of Rogers [12]. Rogers' innovation-diffusion model shows that factors which influence the diffusion of an innovation are the characteristics of the innovation, communication channels, and the social system, 
all interacting over time. The five characteristics of an innovation which affect the rate of diffusion of that innovation, are: relevant advantage (the degree to which the potential adopter perceives the innovation to be better than its forerunner); compatibility (the degree to which the potential adopter perceives the innovation as being in line with his/her existing values, needs and past experiences); complexity (the degree to which the potential adopter experiences the innovation as being difficult to use); observability (the degree to which an innovation's results are evident to others); and "trialability" (the degree to which the potential adopter will try-out the innovation before adoption).

Moore \& Benbasat [9] added two more innovation characteristics to the model of Rogers, namely: image (the degree to which a potential adopter's image or status is perceived to be enhanced in his/her social system because of him/her using the innovation) and voluntariness of use (the degree to which the potential adopter is perceived to willingly make use of the innovation). They furthermore split observability into result demonstrability (the degree to which the potential adopter's results of using the innovation are observable and communicable to others) and visibility (the degree to which information technology is apparent to the sense of sight). Moore and Benbasat [9] also pointed out that the key to whether or not an innovation diffuses is not really a result of the potential adopter's perceptions of the technology itself, but rather his/her perceptions of using the technology. They therefore rephrased Rogers' five innovation characteristics to reflect that it is the perceptions about using the innovation rather than the perceptions about the innovation itself which are of concern, and in addition labelled it "the Perceived Characteristics of Innovation (PCI)".

The social system's characteristics referred to in Rogers' model include those of the individuals, groups, the organisation, decision makers, and specific role players such as champions and senior managers, while the communication channels referred to could be internal or external to the organisation and could transfer either formal or informal communication [12].

According to Rogers [12,13] the diffusion process consists of two stages: adoption and implementation. The adoption stage comprises of three sub-stages: knowledge acquisition, persuasion and learning, and the decision to adopt or reject the innovation. Implementation occurs when the individual starts to use the innovation. Kwon \& Zmud [8] extended this model to also include postimplementation phases, such as confirmation, which occurs when the individual seeks the reinforcement of the innovation-decision already made.

Kwon \& Zmud [8] combined the diffusion of innovation theory with application implementation research and as a result ended up with an enlarged model, which apart from Rogers' model, also includes task (uncertainty, autonomy, and variety) and environmental (heterogeneity, uncertainty, competition, concentration/dispersion, and inter-organisation interdependence) characteristics.

This model can be critiqued in a number of ways. For example, terminology in IT research seems to differ from that used in classic diffusion research, as for the 
former the adoption of technology is often a decision taken by a higher authority and the IS department then gets tasked to diffuse the technology through the rest of the organisation. The decision to adopt the technology is therefore made without consulting all the individuals in the organisation [2]. Adoption is therefore seen as the decision to use the technology, while diffusion is the process of implementing the decision.

Furthermore, in the IT field, voluntary decisions to adopt an innovation are not very common and Rogers' model does not address the resentment which is often caused by the enforcement of IT from a higher authority. Bayer \& Melone [2] also argue that the characteristics of "non-diffusion" are of major importance to the IT field, due to the high incidence of IS failure, and that the classic diffusion theory does not explain why innovations are discarded in the same depth as why it is adopted.

The classic diffusion theory also fails to "consider interactions between various social systems" [2]. Information technologists tend to be more loyal to their discipline than to the organisations that employ them. It is therefore seldom the needs of their organisation that alerts them of a new technology, but rather their contact with other technologists. Aspects such as information politics and power bases seems to be important adoption factors and should therefore also be included in the innovation adoption theory.

According to Du Plooy [5] the classic diffusion theory disappoints as it makes no explicit mention of the social context or human environment of information systems adoption and use. Information technology is socially constructed and to cultivate and nurture a human environment in which the IS is to be implemented, one has to understand how people view technology and how they understand the meaning of technology. Innovation theory and the enhanced models of information technology diffusion/adoption not only fail in their lack of consideration of social interaction, but also because they are overly simplistic (even deterministic) in their view of the innovation process (or, in terms of information technology, of the process of implementation). According to Du Plooy [5]:

"they fail to consider the type of social characteristics and dual interaction between information technology and the organisation, specifically with regard to factors and characteristics such as the different world views of the agent of change and the organisation within which the change is implemented; the duality of technology; the technological frames of reference of the agent of change and the organisation; organisational culture; organisational learning and emergence; the power bases of individuals and groups; empowerment/disempowerment of workers through information technology; resistance to change; the non-deterministic aspects of information technology; the determining capability of this technology; the influence of this technology on the values and judgement of an organisation; the influence of this technology on 
business processes, organisational learning and internal communication; the application of technology in different work situations, e.g. managerial, individual office work, group work; the influence of organisations on information technology; the adaptation of the organisation to the technology; organisational norms and values; etc."

Du Plooy [5] therefore argues that the social context within which the adoption and diffusion of IT takes place is much 'deeper' than the pure demographic characteristics described by the characteristics of Rogers' model. Furthermore, Du Plooy argues that making sense of IT also means understanding the changes in structure, culture, work processes, and power bases that the adoption and use of IT bring to the organisation. Du Plooy extended the enhanced diffusion/ implementation model of Kwon \& Zmud by adding a sixth dimension to the innovation-diffusion process, namely group characteristics. He also added "forces" and "elements" to the other five characteristics which he regarded as of importance to the human environment of IT adoption and use (see Figure 1).

Du Plooy's [5] enhancement of Kwon \& Zmud's diffusion/implementation model is still a deterministic model as it seems to indicate that adoption and use will be successful if one takes the stipulated social factors into consideration when implementing an innovation. Du Plooy [5], however, believes the mechanistic causal interpretation suggested by the model to be incorrect and inappropriate since information technology is socially constructed and has non-deterministic characteristics. One cannot predict outcomes or determine cause and effect during information technology adoption and use that readily, because of these characteristics.

For more successful adoption and use, one needs to understand the social context of IT diffusion and implementation in its totality. This does however not mean that cultivating all six characteristics will guarantee success, while omitting one of these characteristics will also not necessarily lead to the adoption not being successful. According to Du Plooy [5] "such determinism cannot be superimposed on a process with so many non-deterministic characteristics." The six characteristics of Du Plooy's human environment of adoption and use framework (see Figure 2) should be viewed as an integrated totality which is not divisible into parts [5]:

"The six characteristics do not deterministically decide adoption and use. As a whole they are adoption and use in the sense that they constitute the full social context for adoption and use. Taken together they are the very substance of information technology adoption and use."

The "binding factor" between the various characteristics of the framework is their social contexts. Although each side of the cube points to a different dimension of the social context of information technology adoption and use, these dimensions cannot be isolated and considered on their own. The human environment only makes sense when considered in its totality, as a single 


\section{Social Dimensions of ICT Policy}

environment which interacts recursively with information technology during its implementation and during its use [5].

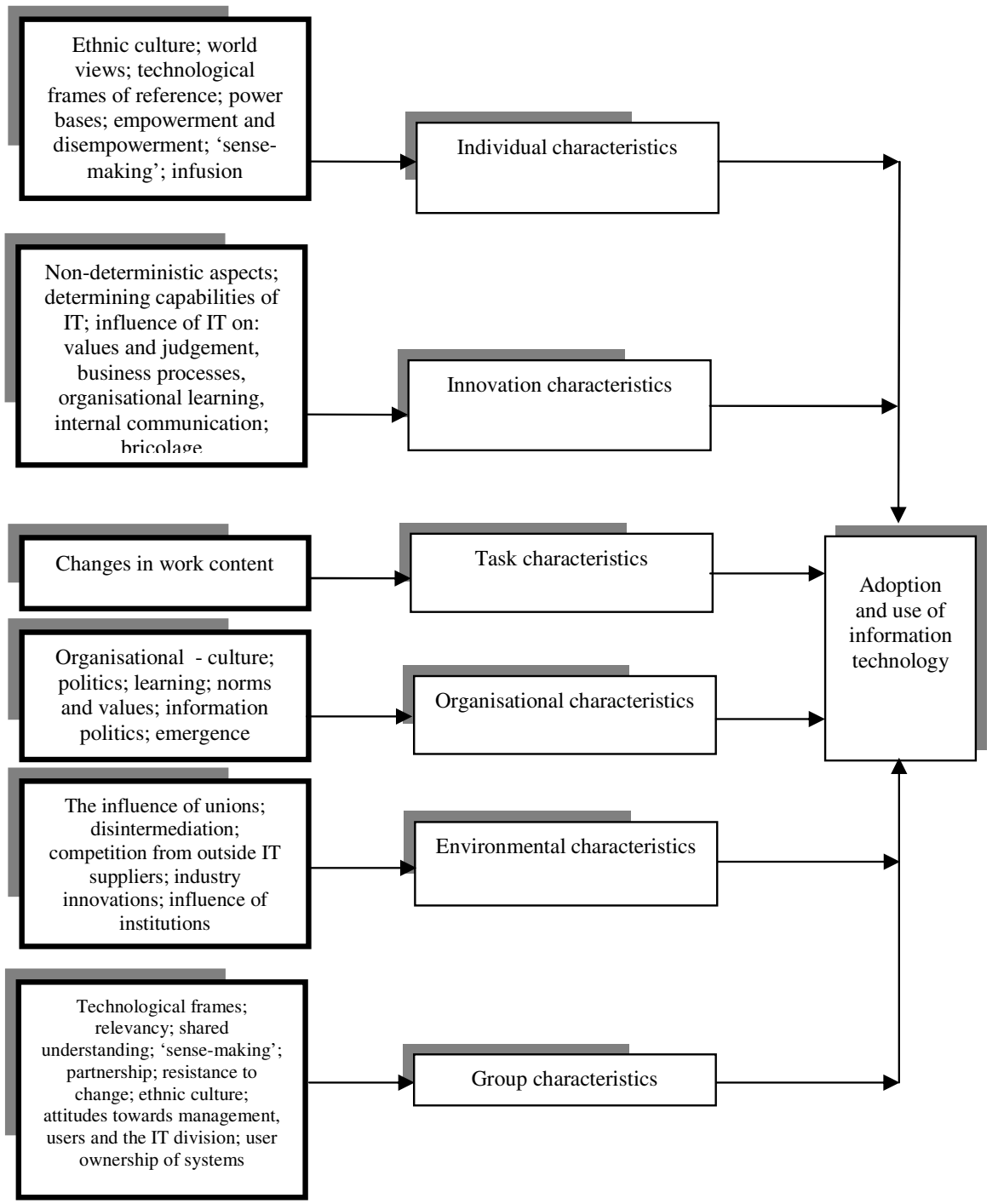

Figure 1: Du Plooy's enhancement of Kwon \& Zmud's diffusion/ implementation model [5]. 


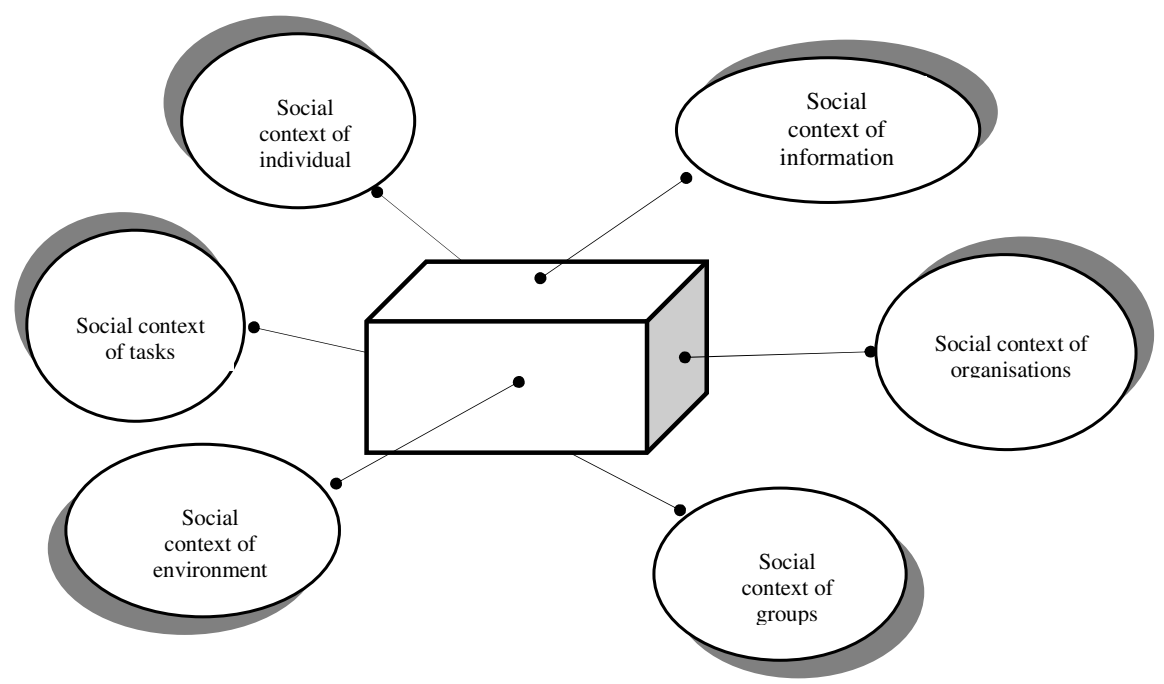

Figure 2: The human environment of IT adoption and use [5].

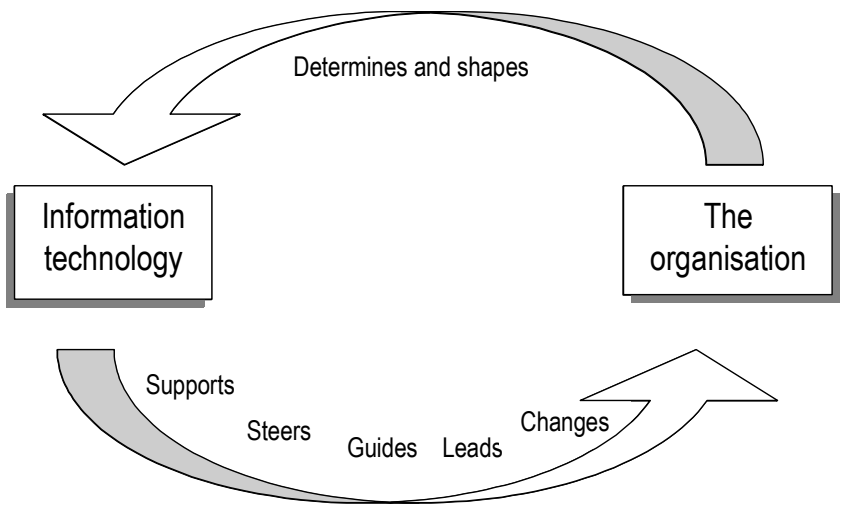

Figure 3: The recursive relationship between information technology and the organisation during the process of adoption and use [5].

Giddens' structuration theory [10] can be applied to describe the processes through which ICT's are themselves shaped, while they at the same time contribute to the shaping of the social relations of organisations within which they are implemented (the duality of technology) (Figure 3). 
The use of Du Plooy's [5] framework to understand the full social context of information technology adoption and use is best understood when the recursive relationship between information technology and the organisation during the process of adoption and use (as illustrated in Figure 3) is integrated with the human environment framework (Figure 2) to show how the human environment actually encapsulates the process of information technology adoption and use (Figure 4).

If we therefore understand the interaction between the human environment and the process of IT adoption and use as shown in figure 4, we are able to make sense of this human environment. Only if we understand the human environment and its interaction with the adoption and use processes will we be able to cultivate and nurture such an environment to facilitate the adoption and use of this technology $[5]$.

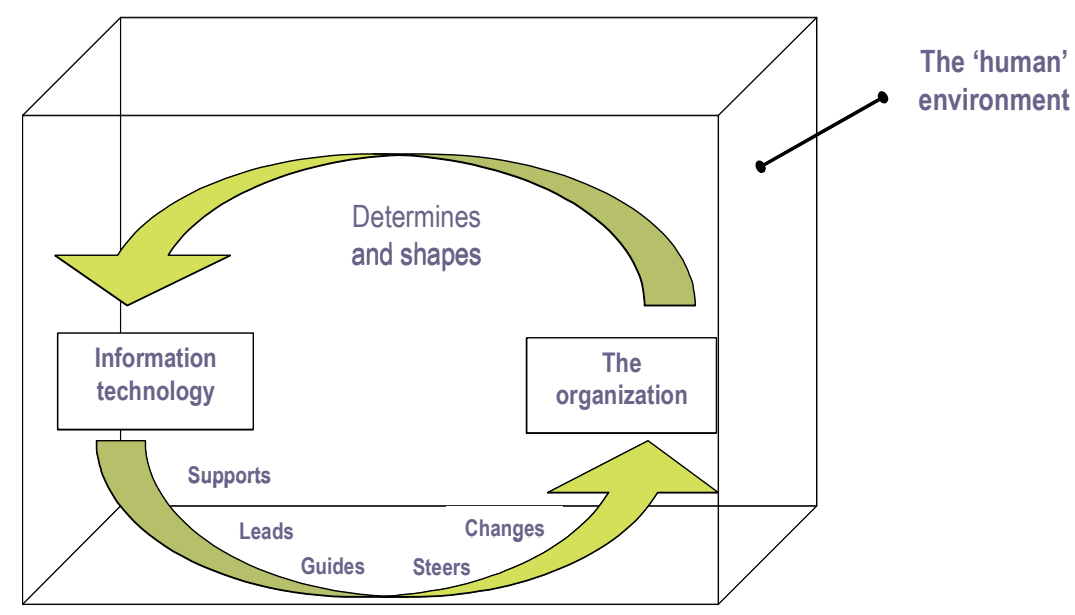

Figure 4: The human environment encapsulating information technology adoption and use [5].

According to Du Plooy [5], it is also important to note that the two dimensions of the adoption and use process shown here are "two sides of the same coin". They are not divisible into two distinct dimensions that can be considered separately because they are both contained and embedded in a human environment. The upper arrow of figure 4 shows that information technology is socially constructed, but this model even goes beyond that. Social construction is a term applied to the study of the meanings of technology and how those meanings affect the implementation (the adoption and use) of technology within the organisation [14]. This model includes that notion, but also shows that the human environment comprises of various integrated social contexts which transcend the study of meanings to include a large number of non-deterministic aspects that should be considered during information technology adoption and use. The lower 
arrow shows that information technology may also determine what an organisation is or may become. It does not do so deterministically, but it takes place within a particular human environment. It is the "other side" of the adoption and use "coin" [5].

This duality, however, is not a separation into two things that differ widely from or contradict each other, but it could rather be described as a concept expressed in a different way. Information technology, due to its close interaction with human actors in organisations, has in fact become the relic of modern society. We cannot perform our work in the modern organisation without this technology, but at the same time our organisations and we are changed when we adopt and use this technology $[10,11]$. These two dimensions are impossible to disentangle or undo. We cannot understand the one dimension unless we also understand the other, and as Du Plooy explains "we can no longer even conceptualise information technology without thinking about its implementation", [5]. Thus, an ICT policy which aims to address socio-economic development should have this duality embedded in its policy if it is to address the process of innovation adoption and diffusion of ICTs in its country. The South African ICT policy for education is used as an example of a policy which aims to address socio-economic development, but in a rather linear manner, and inadequately deals with the process of innovation adoption and diffusion.

\section{The South African ICT policy in education}

The draft White Paper on e-Education outlines the views of the South African Ministry of Education's position on the role of ICT in education in South Africa. The overall e-Education policy goal is:

"Every South African learner in the general and further education and training bands will be ICT capable (that is, use ICT confidently and creatively to help develop the skills and knowledge they need to achieve personal goals and to be full participants in the global community) by 2013", [4, chapter 2, paragraph 2.23)].

The listed strategic objectives of the policy are [4, chapter 4]:

- ICT professional development for management, teaching and learning: Every teacher, manager and administrator in general and further education and training must have the knowledge, skills, and support they need to integrate ICT in teaching and learning.

- Electronic content resource development and distribution: The school curriculum in general and further education and training is supported through effective and engaging software, electronic content and online learning resources, and teachers, content developers, and administrators who contribute effectively to these resources. 
- Access to information and communication technology infrastructure: Every teacher and learner in general and further education and training must have access to ICT infrastructure.

- Connectivity: Every teacher and learner in general and further education and training must have access to an educational network and the Internet.

- Community engagement: Schools must work in partnership with families and the wider community to ensure shared knowledge about ICT and extended opportunities for learning and development through ICT.

The key elements of the policy framework are equity, developing norms and standards, [4, chapter 4]. Content should be locally developed and technology should be viewed as a tool and not a solution.

The paper recognises that in order to achieve these objectives a socio-economic approach is needed:

"for South Africans to cross over to the era of the knowledge economy, social exclusion should not be allowed. President Thabo Mbeki has underscored the importance of ICT for social and economic development at numerous South African and international fora. 'We must continue the fight for liberation against poverty, against underdevelopment, against marginalisation' and '... information and communication technology ... is a critically important tool in that struggle" [4, chapter 4, paragraph 1.11].

This encompasses a view of e-Education as going beyond computer literacy and the ability to operate various technologies. It means that learners (students) and educators (teachers):

- apply ICT skills to access, analyse, evaluate, integrate, present, and communicate information;

- create knowledge and new information by adapting, applying, designing, inventing, and authoring information;

- enhance teaching and learning through communication and collaboration by using ICT; and

- function in a knowledge society by using appropriate technology and mastering communication and collaboration skills.

e-Education views ICT as a resource for reorganising schooling and as a tool for whole-school development. It includes ICT as:

- a tool for management and administration;

- a resource for curriculum integration;

- a communication tool;

- a collaborative tool for teachers and learners; and

- a learning environment that advances creativity, communication [4, chapter 4, paragraphs $2.3 \& 2.4]$

Within the draft White Paper the Department of Education outlines some of the potential benefits of ICT, such as improving the quality of learning and teaching, 
providing students with life-long learning opportunities, and readdressing disparities within the educational system. Improved quality of teaching and learning are based on the premise that access to quality educational material is increased through access to technology and that diverse learning styles can be catered for. There is also recognition that simply placing computers in schools is not sufficient. The technology needs to be an integral part of the schools administration and teaching resources. Thus there is recognition that technology can decrease the time school staff spends on class administration, that school children need to be equipped in terms of technology to be fully functioning citizens when they leave school, and that technology should be used as an integral part of the curriculum. This requires capacity development and support mechanisms so that the technology can be sustained and efficiently utilised.

"There are three critical elements that will determine ICT's future as an effective tool for social and economic development. Firstly is cost. Any solution that South Africa adopts has to be cost-effective if we are to meet our developmental demands and to reach the most remote parts of our country. Secondly is sustainability. It is no use having state of the art technology unless it can be sustained. Thirdly is the efficient utilisation of ICT. Deployment of ICT does not guarantee its efficient utilisation. Capacity building and effective support mechanisms must accompany it”, [4, chapter 4, paragraph 1.17].

Thus a rather broad view of ICT is taken in the draft White Paper and there is recognition that it entails a social and economic approach. There is also some recognition, in terms of the stakeholders that need to be involved (school staff, students and parents), that the school is part of a broader context. We will now look at this policy in relation to our above discussion of diffusion and innovation models.

\section{Discussion}

It is interesting to note that in the e-Education policy there is recognition of many of the dimensions that are required for ICT to be adopted in schools, such as social context and capacity development. In Table 1, one can see that the eEducation policy addresses many of the elements of the human-environmental model. Furthermore, it is also interesting that in comparing the human environmental model (Section 2) and the South African ICT policy (Section 3) the diffusion and adoption of ICT is assumed. The elements are not viewed as a cohesive whole, but as separate sides to a box. 


\begin{tabular}{|c|c|c|}
\hline $\begin{array}{c}\text { Social context } \\
\text { element }\end{array}$ & Description & Current e-Education policy position \\
\hline Individual & $\begin{array}{l}\text { Ethnic culture; world views; } \\
\text { technological frames of } \\
\text { reference; power bases; } \\
\text { empowerment and } \\
\text { disempowerment; 'sense- } \\
\text { making'; infusion }\end{array}$ & $\begin{array}{l}\text { Recognition of the need for individual } \\
\text { capacity development. Also recognised } \\
\text { the role of mediators/champions. Aims for } \\
\text { individual capacity development in terms } \\
\text { of use, skills and knowledge gained. }\end{array}$ \\
\hline $\begin{array}{l}\text { Information } \\
\text { Technology }\end{array}$ & $\begin{array}{l}\text { Non-deterministic aspects; } \\
\text { determining capabilities of IT; } \\
\text { influence of IT on: values and } \\
\text { judgment, business processes, } \\
\text { organisational learning, internal } \\
\text { communication; bricolage }\end{array}$ & $\begin{array}{l}\text { Recognises that access to IT is necessary, } \\
\text { but not sufficient and requires local } \\
\text { support mechanisms. }\end{array}$ \\
\hline Task & Changes in work content & Local content needs to be developed. \\
\hline Organisation & $\begin{array}{l}\text { Organisational culture; politics; } \\
\text { learning; norms and values; } \\
\text { information politics; emergence }\end{array}$ & $\begin{array}{l}\text { Recognition of potential of ICT in } \\
\text { decreasing time spent on administration } \\
\text { and as a tool for more effective } \\
\text { management. }\end{array}$ \\
\hline Environment & $\begin{array}{l}\text { The influence of unions; } \\
\text { disintermediation; competition } \\
\text { from outside IT suppliers; } \\
\text { industry innovations; influence of } \\
\text { institutions }\end{array}$ & $\begin{array}{l}\text { Awareness of the influence of the } \\
\text { environment on adoption (recognition of } \\
\text { disparities caused by apartheid and that } \\
\text { content should be locally developed). } \\
\text { Thus, solutions must be cost-effective and } \\
\text { reach the most remote parts of the } \\
\text { country. }\end{array}$ \\
\hline Group & $\begin{array}{l}\text { Technological frames; relevancy; } \\
\text { shared understanding; 'sense- } \\
\text { making'; partnership; resistance } \\
\text { to change; ethnic culture; } \\
\text { attitudes towards management, } \\
\text { users and the IT division; user } \\
\text { ownership of systems }\end{array}$ & $\begin{array}{l}\text { A team comprising teachers, content } \\
\text { developers and administrators is required } \\
\text { to implement the ICT policy. Also } \\
\text { requires that a partnership should be } \\
\text { formed with families and the wider } \\
\text { community. }\end{array}$ \\
\hline
\end{tabular}

Table 1: The human-environmental dimensions and the South African e-Education policy.

There is mention of the need for a champion in the school to drive the process in the school, as well as a person in the community that can drive the external process. However, inherent in the policy is an assumption that by training and recognising that the technology at the school is a valuable resource, adoption will automatically follow. The draft White Paper implicitly adopts an overly simplistic (deterministic) way in which the adoption and use of IT will occur. The different world views of the agents of change and the organisation within which the change is implemented are not included [5]. Issues of power, politics, and culture are not mentioned and little is said about the impact of the innovation process on organisational culture, organisational learning, and change management. The dual interaction between IT and the school is not considered (the duality of 
technology). What is missing is an analysis of the process by which this will occur - the process by which local content is to be developed; how the different disparate technological frames of the individuals and groups who need to support this policy are aligned, and how support is to be given to teachers and students

\section{Conclusion}

An organisation rarely chooses innovation freely, but it is rather determined by "events, trends, pressures, opportunities, or restrictions in the international or national arena" [1]. The situation with South African schools is not any different.

IS innovation should be studied as "a combination of technical/rational and institutional action" [1]. Not only is an IS implementation an intervention which is rationally planned, but several studies have shown that there are subjective, irrational elements of actions within organisations which tend to interfere with the "rational, planned and methodical actions". These social, cultural, or cognitive forces are located within and beyond an organisational setting and in many cases drive the overall organisational performance [1].

IS studies are in essence contextual, as they address a changing entity within its environment (the information system within the organisation). This is also the case when studying the diffusion and adoption of an IS in an organisation, such as a school. The "diffusion of an innovation" is spreading the word about a new idea or innovation. The adoption or rejection of the idea or innovation would, in time, follow diffusion. Adoption is in turn followed by some kind of change in the social system in which the adoption occurred.

When studying the social context of IS diffusion and adoption, one needs to study the technological change brought about (the "content" of change), and the socio-organisational conditions under which it happens (the "context" of change). An IT innovation and its context are so entangled that it would be an oversimplification to see the technology as the content and the society as the context [3]. Such a simplification makes it difficult to understand the multifaceted processes in which technology and humans take part to form socio-technical entities, or in terms of actor-network theory vocabulary, "heterogeneous networks". When studying change in the field of IS, one should therefore not only study the IS innovation as the content of change, but rather the change of heterogeneous networks of organisations and people within which these innovations will play a role.

A useful approach to the formation of ICT policy would be to develop the policy around the six dimensions of Du Plooy's human environmental model [5] and explain the multi-faceted approach of structuration using Giddens' structuration theory [7]. Thus, the authors are of the opinion that understanding, and as Du Plooy [5] puts it "cultivating", the human environment within which the IT is to be implemented, i.e., "the full social context of IT, the organizational, social, political and ethical concerns that govern and influence IT adoption and use", which in the case of ICT education policies relates to the social context of 
the individuals in the school, the school itself, the groups within the school and the community the school serves, the tasks performed and the IT used to perform them, and the broader environment within which the schools are positioned, would enable a more holistic and contextual ICT education policy to be adopted. This approach is currently being used by one of the authors in reviewing the adoption and use of a new open source content management solution in government in South Africa.

\section{References}

[1] Avgerou, C. (2001) The significance of context in information systems and organisational change. Information Systems Journal, 11, 43-63.

[2] Bayer, J. \& Melone, N. (1989). A critique of diffusion theory as a managerial framework for understanding adoption of software engineering innovations. The Journal of Systems and Software, 9, 161-166.

[3] Callon, M. \& Law, J. (1989) On the construction of socio-technical networks: content and context revisited. Knowledge Society, 9, 57-83.

[4] Department of Education. (2004) Transforming learning and teaching through Information and Communication Technologies (ICTs). Draft White Paper on EEducation in Education, S. A. D. O. (Ed.), Pretoria: Formset Printers Office.

[5] Du Plooy, N. F. (1998) An analysis of the human environment for the adoption and use of information technology. Unpublished DCom thesis, Department of Informatics. Pretoria, South Africa, University of Pretoria.

[6] Friedman, T. L. (2006) The world is flat. The globalised world in the twenty-first century, London, Penguin Books.

[7] Giddens, A. (1984) The constitution of society. Outline of the theory of structuration, Cambridge: Polity.

[8] Kwon, T. H. \& Zmud, R. W. (1987) Unifying the fragmented models of information systems implementation, in: Critical Issues in Information Systems Research, Boland, R. J. \& Hirschheim, R. A., eds., John Wiley \& Sons, New York.

[9] Moore, G. C. \& Benbasat, I. (1991) Development of an instrument to measure the perceptions of adopting an information technology innovation. Information Systems Research, 2(3), 192-222.

[10] Orlikowski, W. J. (2000) Using technology and constituting structures: A practice lens for studying technology in organisations, Organisation Science, 11, (4 (July Aug)), 404-428.

[11] Postman, N. 1992. Technopoly: the surrender of culture to technology. Vintage Books: New York

[12] Prescott, M. B. \& Conger, S. A. (1995) Information technology innovations: A classification by IT locus of impact and research approach. DATA BASE Advances, 26(2 \& 3), 20-41.

[13] Rogers, E. M. (1995) Diffusion of innovations, Fourth edition, The Free Press, New York.

[14] Sahay, S., Palit, M. \& Robey, D. (1994). A relativist approach to studying the social construction of information technology. European Journal of Information Systems, 3(4), 248-258.

[15] Walsham, G. \& Sahay, S. (2006) Research on IS in developing countries: Current landscape and future prospects. Information Technology for Development, 12, 7-24. 